\title{
Empathy in Traditional and Cyber Bullying/Victimization Involvement From Early to Middle Adolescence: A Cross Sectional Study
}

\author{
Nafsika Antoniadou ${ }^{1} \&$ Constantinos M. Kokkinos ${ }^{1}$ \\ ${ }^{1}$ Department of Primary Education, School of Education Sciences, Democritus University of Thrace, \\ Alexandroupolis, Greece \\ Correspondence: Professor Constantinos M. Kokkinos, Department of Primary Education, School of Education \\ Sciences, Democritus University of Thrace, N. Hili, GR 68100, Alexandroupolis, Greece. E-mail: \\ kkokkino@eled.duth.gr
}

Received: February 27, 2018

Accepted: March 22, 2018 Online Published: March 24, 2018

doi:10.5539/jedp.v8n1p153

URL: http://doi.org/10.5539/jedp.v8n1p153

\begin{abstract}
The purpose of this study was to investigate the relationship of affective and cognitive empathy with traditional and cyber bullying/victimization experiences among Greek participants who attended the fifth and sixth grade of elementary school ( $\mathrm{n}=126)$, junior high school $(\mathrm{n}=140)$, and senior high school $(\mathrm{n}=157)$. Overall, results indicated negative correlations of empathy (especially affective) with traditional and cyber bullying/victimization. Negative correlations were particularly observed among elementary school participants, while affective empathy was found to be negatively related to bullying involvement, especially among girls. Overall, empathy (especially affective) may not be sufficiently developed among elementary school students, thus precluding them from understanding and caring about others' emotional state. The negative correlation of empathy and cyber-bullying among junior high school participants might be related to the characteristics of computer mediated communication. Implications of the findings are discussed.
\end{abstract}

Keywords: traditional bullying, traditional victimization, cyber-bullying, cyber-victimization, empathy

\section{Introduction}

Empathy refers to the emotional response towards a specific person or group of people that is stimulated by a circumstance (state empathy) (Eisenberg, Eggum, \& Di Giunta, 2010), or the relatively stable personality characteristic influenced by biological and environmental factors (trait empathy) (Nicovich et al., 2005). Most researchers agree that it is distinguished in two dimensions, cognitive empathy (i.e. the ability to recognize and understand others' feelings), and affective empathy which involves arousal to others' emotional state (König, Gollwitzer, \& Steffgen, 2010). Cognitive empathy is related to Theory of Mind and perspective taking and is a prerequisite for experiencing affective empathy (Blair, 2005). Although empathy results from the joint function of the two components (Blair, 2005), these may differ across development and in their role in one's behavior (Kahn, 2002).

Adequate or high empathy constitutes an important skill for social interactions, since it helps children and adolescents understand and regulate their social behavior, express their feelings, develop and maintain positive relationships (e.g., Albiero et al., 2009). It is being consistently identified as a predictor for traditional bullying (TB) and traditional victimization (TV) involvement (Jolliffe \& Farrington, 2006). Although many traditional bullies have been found to lack in both dimensions of empathy (Slonje, Smith, \& Frisén, 2012), those employing indirect TB may have low affective and high cognitive empathy (Jolliffe \& Farrington, 2006), since this type of aggression requires high social and emotional skills to understand group dynamics (Woods et al., 2009). Victims of TB (especially indirect; Woods et al., 2009) frequently lack in both dimensions of empathy which prevents them from understanding and regulating their emotions and behaviors, as well as from comprehending others' emotions and intentions (Kokkinos \& Kipritsi, 2012).

Although physical presence is not necessary for experiencing empathy, non-verbal signs help understanding which acts are perceived as satisfying and are therefore encouraged by other people, and which have violated the social rules and expectations (Blair, 2005). It has been argued that Computer Mediated Communication (CMC) may 
preclude the user from experiencing empathy, since, according to Social Presence and Media Richness theories, several of its forms provide little to none non-verbal signs, which may increase the possibility of aggressive behavior (Cková, Dedkova, Sevcikova, \& Cerna, 2013). Cyber-bullying (CB), a form of bullying materialized through Information and Communication Technologies (ICT), has been found to negatively correlate with empathy (Baldry, Farrington, \& Sorrentino, 2015), since low empathy users are more likely to participate in CB (e.g., Van Noorden, Haselager, Cillessen, \& Bukowski, 2014), and/or cyber-victimization (CV) (SchultzeKrumbholz \& Scheithauer, 2009). Cyber-bullies may feel less remorse for their victims compared to traditional ones and perceive their acts as harmless (e.g., Raskauskas \& Stoltz, 2007), because of their low empathy, which may be further reduced due to their inability to see their victim's reactions (Campbell, Slee, Spears, Butler, \& Kift, 2013). Finally, since CMC lowers users' perception of others' feelings (Suler, 2004), it is possible that students with adequate affective empathy also take part in the CB incidents, since the used means may emotionally distance the users (Brewer \& Kerslake, 2015), and incommode them from understanding the consequences of their actions (Steffgen et al., 2011). Findings regarding the relationship of empathy with CV are still limited and controversial (Schultze- Krumbholz \& Scheithauer, 2009; Van Noorden et al., 2014).

Even though high empathy has repeatedly been implicated as a protective factor against antisocial behavior, the strength of this relationship may be different for the two empathy components (Woolley, 2012). Furthermore, as Kaukiainen et al. (1999) observe, empathy is correlated negatively with every type of aggression, but the magnitude of the correlation may vary depending on the participant's developmental stage.

Based on a series of studies, Björkqvist et al. (2000) have suggested a developmental theory of aggression, according to which young children's aggression is largely physical and later transforms to verbal when the relative skills emerge. Only when necessary social skills become available, aggression may become indirect and manipulative. Therefore, older participants may use indirect aggression more frequently, since they possess the necessary skills. The development of empathy has a significant role in the course of aggression during a person's life.

Although young children tend to show signs of compassion in their first years of life, empathy generally increases with age (Nesdale, Milliner, Duffy, \& Griffiths, 2009), and develops fully during late adolescence, when it plays a pivotal role in social competence (Albiero et al., 2009). Contrary to affective empathy which develops early in life, cognitive empathy develops significantly during elementary school years, in parallel with language capacities which facilitate empathic reflection. As children grow and progress from childhood to adolescence, their ability to empathize develops with the contribution of biologically and environmentally-based factors, with socializing having a great influence though parents and caregivers, as well as peers (McDonald \& Messinger, 2011).

Stimulation of empathy is based on various mechanisms, and young children need more powerful and primary messages for its stimulation, while adolescents' empathy is based on their advanced socio-cognitive skills (Hoffman, 2000). Moreover, as reported by Topcu and Erdur-Baker (2012), empathy is related to watching the emotional reactions of the other, and while in the case of TB feedback is given by the victim's reactions (gestures, posture, expressions, voice tone), ICT may lower the possibility that the cyber-bully experiences empathy.

Even though contradicting evidence exists, overall, previous findings suggest that boys and students attending junior high school are more frequently involved in CB and TB as bullies, while younger students may be victimized more often (e.g., Varjas et al., 2010). Significant differences have also been found in terms of empathy, since girls tend to have higher scores, a finding which has often been attributed to social expectations regarding gender role, but also to phylogenetic and ontogenetic factors (Christov-Moorea et al., 2014). Boys' predominant participation in both TB and CB incidents has been linked to lower empathy (Topcu \& Erdur-Baker, 2012).

A limited number of studies have investigated the relationship of empathy with bullying among different developmental stages, but, to our knowledge, no study has examined the relationship of both $\mathrm{CB} / \mathrm{CV}$ and TB/TV with the two dimensions of empathy. Since empathy skills, as well as bullying behavior patterns, differ across development, it is valuable in terms of prevention and intervention to examine if empathy is differently related to $\mathrm{CB} / \mathrm{CV}$ and TB/TV among participants of different age. Previous evidence has already suggested that both dimensions of empathy are differentially related to aggression across the course of development. It is interesting to further investigate if $\mathrm{CB}$ and $\mathrm{CV}$ involvement (taking place in a context with limited nonverbal signs that decreases the likelihood of empathy manifestation), is related in the same way to both empathy dimensions as does the involvement in TB/TV, and furthermore, what correlation patterns are observed across age and gender. While research systematically shows a significant correlation between $\mathrm{CB}$ and $\mathrm{TB}$ on one hand, and CV and TV on the other, recent evidence suggests that the phenomena and their risk factors might differ due to the context of implementation (Antoniadou \& Kokkinos, 2015). 
Therefore, the purpose of this study was to investigate the relationship of affective and cognitive empathy with the involvement in TB, TV, CB and CV from early to middle adolescence, among participants attending the final elementary school grades, junior high (Note 1), and senior high school (Note 2) in a cross-sectional design. Thus, specific hypotheses were tested:

H1: Junior high school students and boys will be more frequently involved in $\mathrm{CB} / \mathrm{CV}$ and $\mathrm{TB} / \mathrm{TV}$ incidents.

$\mathrm{H} 2$ : Older participants and girls will have higher scores in empathy.

$\mathrm{H} 3$ : Both $\mathrm{CB} / \mathrm{CV}$ and $\mathrm{TB} / \mathrm{TV}$ will be negatively related to empathy. Higher negative correlations are expected between $\mathrm{CB} / \mathrm{CV}$ and empathy.

H4: A pattern of negative correlations between empathy, TB/TV and $\mathrm{CB} / \mathrm{CV}$ is expected among students of younger age.

H5: A pattern of negative correlations between empathy, TB/TV and $\mathrm{CB} / \mathrm{CV}$ is expected among boys.

\section{Method}

A proportionally stratified sample of 420 participants from Northern Greece and Southern Aegean, 126 (30\%) attending the fifth and sixth grade, 140 (32.6\%) junior high school, and 157 (37.4\%) senior high school participated in the study. Among these, 206 (49\%) were boys, 212 girls (50.5\%), while 2 did not report their gender $(.5 \%)$.

Participants took part in the study voluntarily, after they had been informed about its purposes, anonymity and confidentiality, and parental consent forms had been obtained. Few students refused participation $(<1 \%)$. Questionnaires were administered within one class period (45') in participants' regular classrooms, after permission was received by the Institute of Education Policy, the scientific and consulting body of the Greek Ministry of Education, Research and Religious Affairs. The present research received no specific grant from any funding agency.

\subsection{Measures}

Cyber-bullying/victimization experiences. The Cyber-Bullying and Victimization Experiences Questionnaire-Greek (CBVEQ-G) (Antoniadou, Kokkinos, \& Markos, 2016a) assesses the occurrence of a representative range of direct and indirect $\mathrm{CB} / \mathrm{CV}$ behaviors during the last 90 days with the use of a five-point frequency scale $(1=$ Never, $5=$ Every day $)$ among children and adolescents. The use of the CBVEQ-G in studies among pre-adolescent (Antoniadou \& Kokkinos, 2013; Kokkinos, Antoniadou, Dalara, Koufogazou, \& Papatziki, 2013; Kokkinos, Antoniadou, Asdre, \& Voulgaridou, 2016) and adolescent participants (Antoniadou \& Kokkinos, 2013; Antoniadou, Kokkinos, \& Markos, 2016b; Kokkinos \& Voulgaridou 2017) has shown adequate reliability and indicated the existence of separate but correlated factors (i.e. CB and CV). Internal consistency for the CV scale was .88 for the total sample (.91 for elementary school, .90 for junior high school, and .78 for senior high school participants), and for the CB scale .93 for the total sample (.92 for elementary school, .92 for junior high school, and .93 for senior high school participants).

Traditional Bullying/Victimization. Twenty-four items were used from the Student Survey of Bullying Behavior-Revised 2 (SSBB-R2), which assess TB/TV experiences (direct, verbal and relational) rated on a 5-point Likert scale $(0=$ Never to $4=$ Almost daily), among pre-adolescents and adolescents (Varjas, Meyers, \& Hunt, 2006). The SSBB-R2 has been found to have adequate psychometric properties when used with Greek-speaking samples, while previous studies have verified that the items used in this study load into two different factors (TB and TV) (e.g., Antoniadou, et al., 2016b; Fanti, et al., 2009; Varjas, et al., 2010). Internal consistency of the TV scale was .91 for the total sample (.85 for elementary school, .93 for junior high school, and .86 for senior high school participants), and of the TB scale .94 for the total sample (.91 for elementary school, .94 for junior high school, and .94 for senior high school participants).

Empathy. The 20-item Basic Empathy Scale (BES) (Jolliffe \& Farrington, 2006) assesses cognitive (9 items) and affective empathy (11 items) on a five-point scale $(1=$ Strongly disagree to $5=$ Strongly agree $)$, among pre-adolescents and adolescents. Factor analysis has confirmed that items load into their respective factors (Joliffe \& Farrington, 2006), while BES has been successfully used in previous studies among Greek pre-adolescent and adolescent participants (Antoniadou \& Kokkinos, 2013; Kokkinos \& Kipritsi, 2017). Cronbach's alpha for cognitive empathy was. 78 for the total sample (.75 for elementary school, .71 for junior high school, and .85 for senior high school participants) and for affective empathy .62 (.68 for elementary school, .60 for junior high school, and .68 for senior high school participants). Three items were deleted from the affective scale due to low factor loadings. 


\section{Results}

\subsection{Descriptive Statistics}

Overall, participants reported more frequent involvement in TV, followed by TB, CV and CB. Cognitive empathy scores were also higher than affective empathy (Table 1).

Table 1. Descriptive Statistics

\begin{tabular}{lll}
\hline & Mean & Standard Deviation \\
\hline Cyber- victimization & 1.26 & .44 \\
Cyber- bullying & 1.23 & .51 \\
Traditional Victimization & 1.92 & .79 \\
Traditional Bullying & 1.80 & .88 \\
Affective Empathy & 3.41 & .65 \\
Cognitive Empathy & 3.84 & .67 \\
\hline
\end{tabular}

Note. Range $=1-5$.

\subsection{Correlations}

Significant positive correlations were observed between $\mathrm{CB}$ and CV, TB and CB, TV and CV, TB and TV and between TV and CB, as well as TB and CV. Significant negative correlations emerged between cognitive empathy and $\mathrm{CB}$, while affective empathy had a negative association with $\mathrm{CV}, \mathrm{CB}$ and $\mathrm{TB}$ (Table 2).

Table 2. Correlations in Total Sample

\begin{tabular}{lllllll}
\hline & $\mathrm{CV}$ & $\mathrm{CB}$ & $\mathrm{TV}$ & $\mathrm{TB}$ & $\mathrm{CE}$ & $\mathrm{AE}$ \\
\hline $\mathrm{CB}$ & $.67^{* *}$ & -- & & & & \\
$\mathrm{TV}$ & $.40^{* *}$ & $.25^{* *}$ & -- & & & \\
$\mathrm{TB}$ & $.38^{* *}$ & $.52^{* *}$ & $.53^{* *}$ & -- & & \\
$\mathrm{CE}$ & -.07 & $-.13^{* *}$ & -.04 & -.08 & -- & - \\
$\mathrm{AE}$ & $-.10^{*}$ & $-.17^{* *}$ & -.05 & $-.25^{* *}$ & $.57^{* *}$ & - \\
\hline
\end{tabular}

Note. $\mathrm{CV}=$ Cyber-victimization, $\mathrm{CB}=$ Cyber-bullying, $\mathrm{TV}=$ Traditional Victimization, $\mathrm{TB}=$ Traditional Bullying, $\mathrm{AE}=$ Affective Empathy, $\mathrm{CE}=$ Cognitive Empathy. ${ }^{* *} p<.01,{ }^{*} p<.05$.

\subsection{Gender Differences}

ANOVA tests indicated significant gender differences in terms of affective $F(1,411)=72.53, p<.01$ and cognitive empathy $F(1,411)=49.29, p<.01$ with girls scoring higher in both affective $(M=3.66)$ and cognitive empathy $(M=4.05)$ than boys $(M=3.15$ and $M=3.62$ respectively). A Mann-Whitney test, performed due to homogeneity invariance, indicated that boys scored higher in TB $[U=17.38, p<.01]$ than girls.

Among the boys of the total sample, $\mathrm{CV}$ had a strong positive correlation with $\mathrm{CB}$, and moderate positive correlations with TV and TB. CB had a weak positive correlation with TV and a moderate with TB, while TB had a weak positive correlation with TV. In terms of empathy, only affective empathy had a weak negative correlation with TB (Table 3). Among the girls of the total sample, CV had a moderate positive correlation with CB and weak positive correlations with TV and TB, CB had a weak positive correlation with TV and a moderate positive with TB, while TB had a moderate positive correlation with TV. Affective empathy had weak negative correlations with $\mathrm{CB}$ and TB, while cognitive empathy had a weak correlation with CB (Table 3). 
Table 3. Correlations among Boys $(n=206)$ and Girls $(n=212)$

\begin{tabular}{|c|c|c|c|c|c|c|c|}
\hline & & CV & CB & TV & TB & $\mathrm{AE}$ & $\mathrm{CE}$ \\
\hline \multirow{2}{*}{ CB } & Boys & $.73^{* *}$ & -- & & & & \\
\hline & Girls & $.51^{* *}$ & -- & & & & \\
\hline \multirow{2}{*}{ TV } & Boys & $.38^{* *}$ & $.24^{* *}$ & -- & & & \\
\hline & Girls & $.42^{* *}$ & $.25^{* *}$ & -- & & & \\
\hline \multirow{2}{*}{$\mathrm{TB}$} & Boys & $.40^{* *}$ & $.51^{* *}$ & $.49^{* *}$ & -- & & \\
\hline & Girls & $.33^{* *}$ & $.54^{* *}$ & $.59^{* *}$ & -- & & \\
\hline \multirow{2}{*}{$\mathrm{AE}$} & Boys & -.10 & -.04 & -.01 & $-.17^{*}$ & -- & \\
\hline & Girls & -.05 & $-.29^{* *}$ & -.05 & $-.25^{* *}$ & -- & \\
\hline \multirow{2}{*}{ CE } & Boys & -.06 & -.00 & -.04 & .02 & $.42^{* *}$ & -- \\
\hline & Girls & -.04 & $-.26^{* *}$ & .01 & -.06 & $.58^{* *}$ & -- \\
\hline
\end{tabular}

Note. $\mathrm{CV}=$ Cyber-victimization, $\mathrm{CB}=$ Cyber-bullying, $\mathrm{TV}=$ Traditional Victimization, $\mathrm{TB}=$ Traditional Bullying, $\mathrm{AE}=$ Affective Empathy, $\mathrm{CE}=$ Cognitive Empathy. $* * p<.01, * p<.05$.

\subsection{Developmental Stage Differences}

ANOVA tests indicated significant differences between participants of different age in terms of TV $F(1,412)=$ $39.46, p<.01$, with junior high school students scoring higher $(M=2.37)$ than elementary $(M=1.73)$ and senior high school students $(M=1.67)$. A series of Kruskal Wallis tests, performed due to homogeneity invariance, showed that junior high school participants reported more TB $\left[\chi^{2}(2, N=417)=96.47, p<.01\right]$ than elementary and junior high school ones, while elementary school students reported less $\mathrm{CV}\left[\chi^{2}(2, N=416)=13.32, p<.01\right]$ and $\mathrm{CB}\left[\chi^{2}(2, N=416)=20.73, p<.01\right]$ than junior and senior high school students.

Correlations between CB, CV, TB and TV among participants of different age were calculated (Table 4). Among all age-groups, moderate to high correlations were observed between $\mathrm{CB}$ and $\mathrm{CV}$, and $\mathrm{CB}$ with $\mathrm{TB}$, both of which were highest among junior high school students. Cognitive empathy had moderate correlations with affective empathy among all age-groups, while affective significant negative correlations with CV among elementary school students, and CB and TB among elementary and senior high school students. Cognitive empathy had a significant negative correlation with CB among junior high school students, and negative correlations with TV among elementary and senior high school students.

Table 4. Correlations between Elementary $(n=126)$, Junior High $(n=140)$ and Senior High $(n=157)$ School Participants

\begin{tabular}{|c|c|c|c|c|c|c|c|}
\hline & & $\mathrm{CV}$ & $\mathrm{CB}$ & TV & TB & $\mathrm{AE}$ & $\mathrm{CE}$ \\
\hline \multirow{3}{*}{$\mathrm{CB}$} & Elementary & $.71^{* *}$ & -- & & & & \\
\hline & Junior & $.83^{* *}$ & -- & & & & \\
\hline & Senior & $.50^{* *}$ & -- & & & & \\
\hline \multirow{3}{*}{$\mathrm{TV}$} & Elementary & $.23 *$ & .15 & -- & & & \\
\hline & Junior & $.49 * *$ & $.45^{* *}$ & -- & & & \\
\hline & Senior & $.43 * *$ & $.18^{*}$ & -- & & & \\
\hline \multirow{3}{*}{ TB } & Elementary & $.23^{*}$ & $.54 * *$ & $.45^{* *}$ & - & & \\
\hline & Junior & $.51 * *$ & $.58 * *$ & $.65^{* *}$ & -- & & \\
\hline & Senior & $.39 * *$ & $.54^{* *}$ & $.34 * *$ & -- & & \\
\hline \multirow{3}{*}{$\mathrm{AE}$} & Elementary & $-.23^{*}$ & $-.29^{* *}$ & -.10 & $-.29 * *$ & - & \\
\hline & Junior & -.02 & -.11 & .01 & -.15 & -- & \\
\hline & Senior & -.07 & $-.17 *$ & -.01 & $-.31 * *$ & -- & \\
\hline
\end{tabular}




\begin{tabular}{|c|c|c|c|c|c|c|c|}
\hline & Elementary & -.12 & -.16 & $-.25 * *$ & -.17 & $.59^{* *}$ & -- \\
\hline \multirow[t]{2}{*}{$\mathrm{CE}$} & Junior & -.16 & $-.21^{* *}$ & -.12 & -.09 & $.53^{* *}$ & -- \\
\hline & Senior & -.01 & -.10 & $-.16^{*}$ & -.10 & $.56^{* *}$ & -- \\
\hline
\end{tabular}

Note. $\mathrm{CV}=$ Cyber-victimization, $\mathrm{CB}=$ Cyber-bullying, $\mathrm{TV}=$ Traditional Victimization, $\mathrm{TB}=\mathrm{Traditional} \mathrm{Bullying}, \mathrm{AE}=$ Affective Empathy, $\mathrm{CE}=$ Cognitive Empathy. ${ }^{* *} p<.01, * p<.05$

\section{Discussion}

In line with the initial expectation, TB and TV involvement was higher among junior high school participants and decreased in senior high school, while CV was lower in elementary school (H1). Participation in bullying incidents has often been attributed to pre-adolescents' effort to establish their position in the peer group (Varjas et al., 2010). As expected (H1), boys had higher scores in TB (Topcu \& Erdur-Baker, 2012).

In terms of empathy (H2), both its cognitive and affective component increased with age, which was expected due to the developmental course of empathy (Hoffman, 2000), but the difference was marginally insignificant. In line with H2, girls reported higher cognitive and affective empathy (Christov-Moorea et al., 2014).

Overall, cognitive empathy was negatively correlated to $\mathrm{CB}$, while affective was negatively correlated to $\mathrm{CV}, \mathrm{CB}$ and TB (H3). According to research, cognitive empathy is a pre-requisite for the development of affective empathy (Blair, 2005), but CMC may prohibit its development due to the limited non-verbal signs it provides (Cková et al., 2013). Therefore, users who already have low cognitive empathy may have greater problems understanding others' emotions through CMC. Regarding the negative correlation of affective empathy with CB and TB, studies have shown that deficiencies in affective empathy are generally more strongly associated with bullying behavior than those in cognitive empathy, since low affective empathy may inhibit the aggressor from sharing the negative emotional reaction of the victim, thus prolonging bullying behavior (Sutton \& Koegh, 2000). The negative correlation of affective empathy with $\mathrm{CV}$ is in line with previous research (H3) and may suggest that $\mathrm{CB}$ victims have difficulties in recognizing, understanding and regulating emotions which contribute to their victimization, or don't allow them to protect themselves from the incidents (Kokkinos \& Kipritsi, 2012; Woods et al., 2009).

In line with the hypothesis (H4), negative correlations were observed between empathy (especially affective), TV and $\mathrm{CB} / \mathrm{CV}$ among participants attending elementary school. These findings confirmed that among young participants, low affective empathy is a risk factor for bullying involvement (Hoffman, 2000), which may suggest that due to the developing affective empathy they face greater problems than older participants with empathizing (either in the real world or though CMC), and might perceive the acts as harmless. The negative correlation of cognitive empathy with TV in elementary students is in line with previous studies showing that young participants are more frequently victims of older bullies due to their inadequate social skills (Woods et al., 2009). Among junior high school participants, the negative correlation between cognitive empathy and $\mathrm{CB}$ can be linked to the characteristics of CMC (more frequently used in this age group) that further deter accurate understanding of other users' emotions (Suler, 2004). Previous studies have also indicated that cognitive empathy has a stronger connection with aggression in this age group (Van Heerebeek, 2010).

Among senior high school participants, only a weak negative correlation was observed between cognitive empathy and TV, which may be a characteristic of older participants' empathy development (McDonald \& Messinger, 2011). The higher correlation of affective empathy with TB among senior high school students was not expected, but may be attributed to the fact that the students of this sample had higher (although not statistically significant) scores than expected in TB and CB (Varjas et al., 2010).

In terms of gender, contrary to the initial hypothesis (H5), negative correlations were observed between empathy (especially affective) and CB and TB among girls. As previous studies have indicated, affective empathy may be a more significant factor that ameliorates the possibility of bullying involvement in girls, than in boys (Ang \& Goh, 2010).

Overall, findings of this study underline the noteworthy role of empathy in participants' involvement in aggression and contribute to the relevant research, since previous findings on the importance of affective and cognitive empathy in bullying involvement have been inconclusive (Woolley, 2012).

As Björkqvist, Österman and Kaukiainen (2000) observe, empathy training, through role play and other activities that prompt participants to identify with the victims, may be a useful contribution to programs battling aggression. Especially young participants could benefit from learning to understand and care for others' feelings, through exercises that integrate perspective taking, understanding and displaying emotions (Ang \& Goh, 2010). Since 
focus only on the cognitive dimension of empathy has proven ineffective (especially for older participants), anti-bullying programs should address both low empathy components (Jolliffe \& Farrington, 2011). Regarding CMC, which increases significantly during junior high school, parents and educators, could work on participants' understanding of proper online behavior, and accepting that online acts have real effects on users' feelings (Suler, 2004).

Several limitations should be considered in any attempt to generalize the findings; they should be interpreted with caution, since the sample was small. Since this study is cross-sectional in nature, future longitudinal studies may be more suitable for comparative investigation. Furthermore, the use of self-report measures increases the risk of random, hasty and/or socially desirable answers and future research could benefit from the use of multiple sources. Also, some of the observed correlations were weak, while generally due to the correlational nature of the study no conclusions whatsoever can be drawn concerning cause and effect. Future studies could attempt replication of the results among a wider and representative sample. Finally, future studies could examine the role of empathy after controlling for the impact of other variables.

\section{References}

Albiero, P., Matricardi, G., Speltri, D., \& Toso, D. (2009). The assessment of empathy in adolescence: A contribution to the Italian validation of the "Basic Empathy Scale". Journal of Adolescence, 32, 393-408. https://doi.org/10.1016/j.adolescence.2008.01.001.

Ang, R. P., \& Goh, D. H. (2010). Cyberbullying among adolescents: The role of affective and cognitive empathy, and gender. Child Psychiatry and Human Development, 41, 387-397. https://doi.org/10.1007/s10578-010-0176-3.

Antoniadou, N., \& Kokkinos, C. M. (2013). Cyber bullying and cyber victimization among children and adolescents: Frequency and risk factors. Preschool and Primary Education, 1, 138-169. https://doi.org/dx.doi.org/10.12681/ppej.42.

Antoniadou, N., \& Kokkinos, C. M. (2015). Cyber and school bullying: same or different phenomena? Aggression and Violent Behavior, 25, 363-372. https://doi.org/10.1016/j.avb.2015.09.013.

Antoniadou, N., Kokkinos, C. M., \& Markos, A. (2016a). Development, construct validation and measurement invariance of the Greek Cyber-bullying/victimization Experiences Questionnaire (CBVEQ-G). Computers in Human Behavior, 65, 380-390. https://doi.org/10.1016/j.chb.2016.08.032.

Antoniadou, N., Kokkinos, C. M., \& Markos, A. (2016b). Possible common correlates between bullying and $\begin{array}{lllll}\text { cyber-bullying among } \quad \text { adolescents. Psicología Educativa, 22, } & \text { 27 }\end{array}$ https://doi.org/10.1016/j.pse.2016.01.003.

Baldry, A. C., Farrington, D. P., \& Sorrentino, A. (2015). Am I at risk of cyberbullying? A narrative review and conceptual framework for research on risk of cyberbullying and cybervictimization: The risk and needs assessment approach. Aggression and Violent Behavior, 23, 36-51. https://doi.org/10.1016/j.avb.2015.05.014.

Björkqvist, K., Österman, K., \& Kaukiainen, A. (2000). Social intelligence- empathy= aggression? Aggression and Violent Behavior, 5, 191-200. https://doi.org/10.1016/S1359-1789(98)00029-9.

Blair, R. J. R. (2005). Responding to the emotions of others: Dissociating forms of empathy through the study of typical and psychiatric populations. Consciousness and Cognition, 14, 698-718. https://doi.org/10.1016/j.concog.2005.06.004.

Brewer, J. \& Kerslake, G. (2015). Cyberbullying, self-esteem, empathy and loneliness. Computers in Human Behavior, 48, 255-260. https://doi.org/10.1016/j.chb.2015.01.073.

Campbell, M. A., Slee, P. T., Spears, B., Butler, D., \& Kift, S. (2013). Do cyberbullies suffer too? Cyberbullies' perceptions of the harm they cause to others and to their own mental health. School Psychology International, 34, 613-629. https://doi.org/10.1177/0143034313479698.

Christov-Moorea, L., Simpson, E. A., Coudé, G., Grigaitytea, K., Iacobonia, M., Francesco Ferrari, P. (2014). Empathy: Gender effects in brain and behavior. Neuroscience \& Biobehavioral Reviews, 46, 604-627. https://doi.org/10.1016/j.neubiorev.2014.09.001.

Cková, H. M., Dedkova, L., Sevcikova, A., \& Cerna, A. (2013). Bystanders' Support of Cyberbullied Schoolmates. Journal of Community \& Applied Social Psychology, 23, 25-36. https://doi.org/10.1002/casp.2135.

Eisenberg, N., Eggum, N. D., \& Di Giunta, L. (2010). Empathy-Related Responding: Associations with Prosocial Behavior, Aggression, and Intergroup Relations. Social Issues and Policy Review, 4, 143-180. 
https://doi.org/10.1111/j.1751-2409.2010.01020.x.

Fanti, K. A., Frick, P. J., \& Georgiou, S. (2009). Linking callous-unemotional traits to instrumental and non-instrumental forms of aggression. Journal of Psychopathology and Behavioral Assessment, 31, 285-298. http://dx.doi.org/10.1007/s10862-008-9111-3.

Hoffman, M. L. (2001). Empathy and moral development: Implications for caring and justice. Cambridge University Press. https://doi.org/10.1097/00004583-200105000-00026.

Jolliffe, D., \& Farrington D. P. (2006). Examining the role between low empathy and bullying. Aggressive Behavior, 32, 540-550. https://doi.org/10.1002/ab.20154.

Jolliffe, D., \& Farrington, D. P. (2011). Is low empathy related to bullying after controlling for individual and social background variables? Journal of Adolescence, 34, 59-71. https://doi.org/10.1016/j.adolescence.2010.02.001

Kahn, R. E. (2002). Affective and Cognitive Empathy Deficits Distinguish Primary and Secondary Variants of Callous-Unemotional Youth (Unpublished Doctoral Dissertation). Retrieved from $\mathrm{http} / /$ scholarworks.uno.edu/cgi/viewcontent.cgi?article=2925\&context=td.

Kaukiainen, A., Björkqvist, K., Lagerspetz, K., Österman, K., Salmivalli, C., Rothberg, S., \& Ahlbom, A. (1999). The relationships between social intelligence, empathy, and three types of aggression. Aggressive Behavior, 25, 81-89. https://doi.org/10.1002/(SICI)1098-2337(1999)25:2<81::AID-AB1>3.0.CO;2-M.

Kokkinos, C. M., Antoniadou, N., Asdre, A., \& Voulgaridou, K. (2016). Parenting and Internet Behavior Predictors of Cyber-bullying and Cyber-victimization among Preadolescents. Deviant Behavior, 37, 439-455. https://doi.org/10.1080/01639625.2015.1060087.

Kokkinos, C. M., Antoniadou, N., Dalara, E., Koufogazou A., \& Papatziki, A. (2013). Cyber-bullying, personality traits and coping strategies in pre-adolescent students. International Journal of Cyber Behavior, Psychology and Learning, 3, 55-69. https://doi.org/10.4018/ijcbpl.2013100104.

Kokkinos, C. M., \& Kipritsi, E. (2012). The relationship between bullying, victimization, trait emotional intelligence, self-efficacy and empathy among preadolescents. Social Psychology of Education, 15, 41-58. https://doi.org/10.1007/s11218-011-9168-9.

Kokkinos, C. M., \& Kipritsi, E. (2017). Bullying, moral disengagement and empathy: exploring the links among early adolescents. Educational Psychology, 1-18. https://doi.org/10.1080/01443410.2017.1363376.

Kokkinos, C. M., \& Voulgaridou, I. (2017). Relational and cyber aggression among adolescents: Personality and emotion regulation as moderators. Computers in Human Behavior, 68, 528-537. https://doi.org/10.1016/j.chb.2016.11.046

König, A., Gollwitzer, M., \& Steffgen, G. (2010). Cyberbullying as an act of revenge? Australian Journal of Guidance \& Counselling, 20, 210-224. https://doi.org/10.1375/ajgc.20.2.210.

McDonald, N. M., \& Messinger, D. S. (2011). The development of empathy: How, when, and why. In J. J. Sanguineti, A. Acerbi, \& J. A. Lombo (Eds.), Moral Behavior and Free Will: A Neurobiological and Philosophical Approach (pp. 341-368). Morolo, Italy: If Press.

Nesdale, D., Milliner, E., Duffy, A., \& Griffiths, J. A. (2009). Group Membership, Group Norms, Empathy, and Young Children's Intentions to Aggress. Aggressive Behavior, 35, 244-258. https://doi.org/10.1002/ab.20303.

Nicovich, S. G., Boller, G. W., \& Cornwell, T. B. (2005). Experienced Presence within Computer - Mediated Communications: Initial Explorations on the Effects of Gender with Respect to Empathy and Immersion. Journal of Computer - Mediated Communication, 10. https://doi.org/10.1111/j.1083-6101.2005.tb00243.x.

Raskauskas, J., \& Stoltz, A. D. (2007). Involvement in Traditional and Electronic Bullying Among Adolescents. Developmental Psychology, 43, 564-575. https://doi.org/10.1037/0012-1649.43.3.564.

Schultze-Krumbholz, A., \& Scheithauer, H. (2009). Social-Behavioral Correlates of Cyberbullying in a German Student Sample. Journal of Psychology, 217, 224-226. http://dx.doi.org/10.1027/0044-3409.217.4.224.

Slonje, R., Smith, P. K., \& Frisen, A. (2012). Processes of cyberbullying, and feelings of remorse by bullies: A pilot study. European Journal of Developmental Psychology, 9, 244-259. https://doi.org/10.1080/17405629.2011.643670.

Steffgen, G., Konig, A., Pfetsch, J., \& Melzer, A. (2011). Are cyberbullies less empathic? Adolescents' cyberbullying behavior and empathic responsiveness. Cyberpsychology, Behavior, and Social Networking, 14, 
643-648. https://doi.org/10.1089/cyber.2010.0445.

Suler, J. (2004). The online disinhibition effect. CyberPsychology \& Behavior, 7, 321-326. https://doi.org/10.1089/1094931041291295.

Sutton, J., \& Keogh, E. (2000). Social competition in school: Relationships with bullying, Machiavellianism and $\begin{array}{llll}\text { personality. British Journal of Educational Psychology, 70, 443-456. } & \text {. }\end{array}$ https://doi.org/10.1348/000709900158227.

Topcu, C., \& Erdur-Baker, O. (2012). Affective and cognitive empathy as mediators of gender differences in cyber and traditional bullying. School Psychology International, 33, 550-561. https://doi.org/10.1177/0143034312446882.

Van Heerebeek, E. C. M. (2010). The Relationship between cognitive and affective empathy and indirect and direct aggression in Dutch Adolescent (Master thesis). Retrieved from dspace.library.uu.nl/handle/1874/188513

Van Noorden, T. H. J., Haselager, G. J. T., Cillessen, A. H. N., \& Bukowski, W. M. (2013). Empathy and Involvement in Bullying in Children and Adolescents: A Systematic Review. Journal of Youth and Adolescence, 44, 637-657. doi: 10.1007/s10964-014-0135-6.

Varjas, K., Meyers, J., \& Hunt, M. H. (2006). Student Survey of Bullying Behavior-Revised 2 (SSBB-R2). Atlanta, Georgia: Georgia State University, Center for Research on School Safety, School Climate and Classroom Management.

Varjas, K., Talley, J., Meyers, J., Parris, L., Cutts, H., \& Hankin, A. (2010). High school students' perceptions of motivations for cyberbullying: an exploratory study. Western Journal of Emergency Medicine, 11, 269-273.

Woods, S., Wolke, D., Nowicki, S., \& Hall, L. (2009). Emotion recognition abilities and empathy of victims of bullying. Child Abuse \& Neglect, 33, 307-311.

Woolley, D. (2012). Deficiencies in Empathy as a Predictor of Aggression in Young Children (Master thesis). Retrieved from http://www.psychology.uct.ac.za/sites/default/files/image_tool/images/117/Danielle.Woolley. pdf

\section{Notes}

Note 1. Gymnasium in Greek; comprised of 3 grades and attended by students aged 12-15 yrs.

Note 2. Lyceum in Greek; comprised of 3 grades and attended by students aged 15-18 yrs.

\section{Copyrights}

Copyright for this article is retained by the author(s), with first publication rights granted to the journal.

This is an open-access article distributed under the terms and conditions of the Creative Commons Attribution license (http://creativecommons.org/licenses/by/4.0/). 